\title{
Cilia, calcium and the basis of left-right asymmetry
}

\author{
Dominic P Norris*
}

\begin{abstract}
The clockwise rotation of cilia in the developing mammalian embryo drives a leftward flow of liquid; this genetically regulated biophysical force specifies left-right asymmetry of the mammalian body. How leftward flow is interpreted and information propagated to other tissues is the subject of debate. Four recent papers have shed fresh light on the possible mechanisms.
\end{abstract}

\section{Opinion}

Although we can instinctively tell left from right, these two terms prove strangely difficult to define. The developing embryo, however, reproducibly performs this task; the mechanisms underlying this process have intrigued embryologists for decades [1]. The human body shows a clear left-right (L-R) asymmetry in the placement and patterning of the internal organs and associated vasculature: the heart apex, stomach and spleen lie to the left and the liver to the right. The normal pattern of sidedness (situs), is called 'situs solitus', whereas a mirrorsymmetric inversion of sidedness is called 'situs inversus'. Situs solitus is seen in almost everyone, so it is clear that the determination of situs is controlled by a robust developmental mechanism. Moreover, organ asymmetry is strongly conserved throughout the vertebrate lineage, arguing that it is of ancient origin and has been evolutionarily conserved. Defects in situs determination are rare, but when they do occur they are particularly associated with congenital heart disease (CHD) [2]. Indeed, it has been argued that very minor situs defects may manifest solely as cardiac defects, suggesting that the heart is more sensitive to situs defects than the other organs $[3,4]$. Strong associations are also seen between L-R defects and many ciliopathies (diseases resulting from defective cilia); this association is due to a requirement for both motile and immotile cilia in L-R determination $[5,6]$. L-R

*Correspondence: d.norris@har.mrc.ac.uk

Mammalian Genetics Unit, MRC Harwell, Harwell Science and Innovation Campus, Oxfordshire, OX11 ORD, UK

(C) 2012 Norris; licensee BioMed Central Ltd. This is an Open Access article distributed under the terms of the Creative Commons Attribution License (http://creativecommons.org/licenses/by/2.0), which permits unrestricted use, distribution, and reproduction in any medium, provided the original work is properly cited. patterning defects also occur at a significant frequency in patients with extrahepatic biliary atresia [7]. The resultant defects in bile-duct function mean that most of these patients require a liver transplant during infancy; the mechanism underlying this association remains unknown, although simple geometric considerations may come into play.

\section{The role of the node in establishing L-R asymmetry in early mammalian development}

In the mouse embryo, the $\mathrm{L}-\mathrm{R}$ axis is established at approximately 8.25 days of development. The 8.25-day embryo is relatively simple; an obvious head and heart lie at the anterior end and a midline containing the notochord runs down the middle, with the pit shaped structure known as the node at its posterior end (Figure 1). Immediately to either side of the midline sits the paraxial mesoderm, containing the somites (from which trunk muscle and skeletal tissue develop). This is flanked by the lateral plate mesoderm (LPM), a lineage that will in later development contribute to asymmetric organ structure. Overlying the mesodermal tissue is a thin layer of endoderm that gives rise to the gut. As revealed in the papers to be discussed here, the endoderm also plays a previously unrecognized part in L-R patterning.

Over the past 15 years, a general model of the establishment of L-R asymmetry has emerged (Figure 1). The first indication that bilateral symmetry of the embryo has been broken is the L-R asymmetric expression of certain genes in regions flanking the node as well as more laterally, in the LPM. Upstream of asymmetric gene expression, the rotation of motile cilia within the node (or the equivalent structure in other vertebrates) causes a leftward flow of fluid, called 'nodal flow' [8-11]. In the mouse, cilia project from the ventral surface of the node; these cilia are polarized with respect to the anteriorposterior axis and by rotating in a clockwise direction, drive nodal flow leftwards [12]. Nodal flow has been shown to be both necessary and sufficient to define the left side of the mouse embryo [13,14]. The high incidence of L-R patterning defects in humans with immotile cilia suggests that the same is true in humans [15]; approximately $50 \%$ of patients with immotile or abnormally 


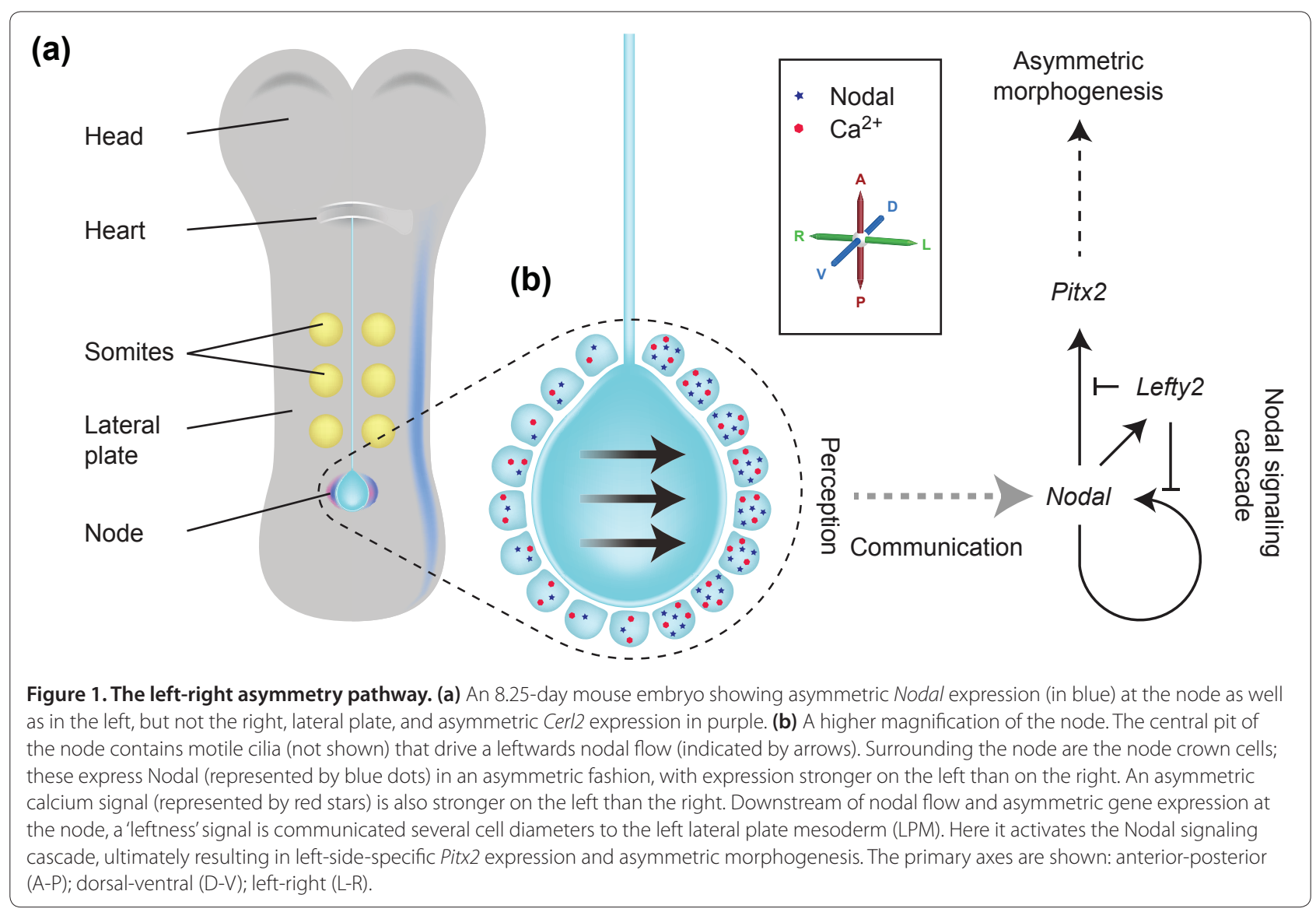

motile cilia exhibit situs inversus [16]. Downstream of nodal flow, asymmetric $\mathrm{Ca}^{2+}$ signaling is seen at the edges of the node, with stronger signaling on the left side than on the right [17]. In the interests of simplicity, this article will focus on our understanding of the determination of L-R asymmetry in the mouse, and will address two questions: how is L-R asymmetry established at the mouse node; and how is that asymmetry subsequently transferred over several cell diameters to the LPM.

\section{Establishing and maintaining asymmetry: the Nodal signaling cascade}

Downstream of the initial breaking of symmetry at the node, the Nodal signaling cascade is activated in the left, but not the right, LPM (Figure 1). Nodal, a member of the transforming growth factor-beta (TGF-beta) signaling family of intercellular signaling proteins, functions as a dimer. Importantly, only those cells in the left and right LPM are competent to respond to Nodal signaling. In the left LPM, Nodal signaling induces expression of the Nodal gene itself, the Lefty 2 gene, which encodes an antagonist of Nodal signaling, and the Pitx2 gene, which encodes a transcription factor that acts downstream of Nodal. Lefty2 is also a TGF-beta family member, but unlike
Nodal it functions as a monomer, and diffuses faster and further than Nodal [18-20]. Once Nodal is expressed in the left LPM, the resultant production of Lefty2 suppresses the Nodal cascade in the right LPM, helping to lock in asymmetry [21]. Nodal and Lefty 2 are expressed for only 6 to 8 hours. In contrast, once activated, Pitx 2 remains asymmetrically expressed in the left LPM for the next two days, so that Pitx2 protein is present in the left LPM during organogenesis [22-24]. This has led to the proposition that Pitx2 is the ultimate effector of leftness [25]. While this is not absolutely the case, asymmetry of Pitx2 expression does underlie asymmetry of many organs $[26,27]$.

\section{Detecting flow in the node: the three hypotheses}

The mechanisms by which nodal flow is 'perceived' by the embryo remain the subject of debate, with three main hypotheses currently in contention (Figure 2). The 'morphogen hypothesis' argues that a short-lived molecule becomes enriched on the left side of the node in response to nodal flow and that this higher concentration on the left is detected, leading to a L-R asymmetric signal [8]. Both computational and experimental investigation argue that such asymmetric enrichment is plausible for 


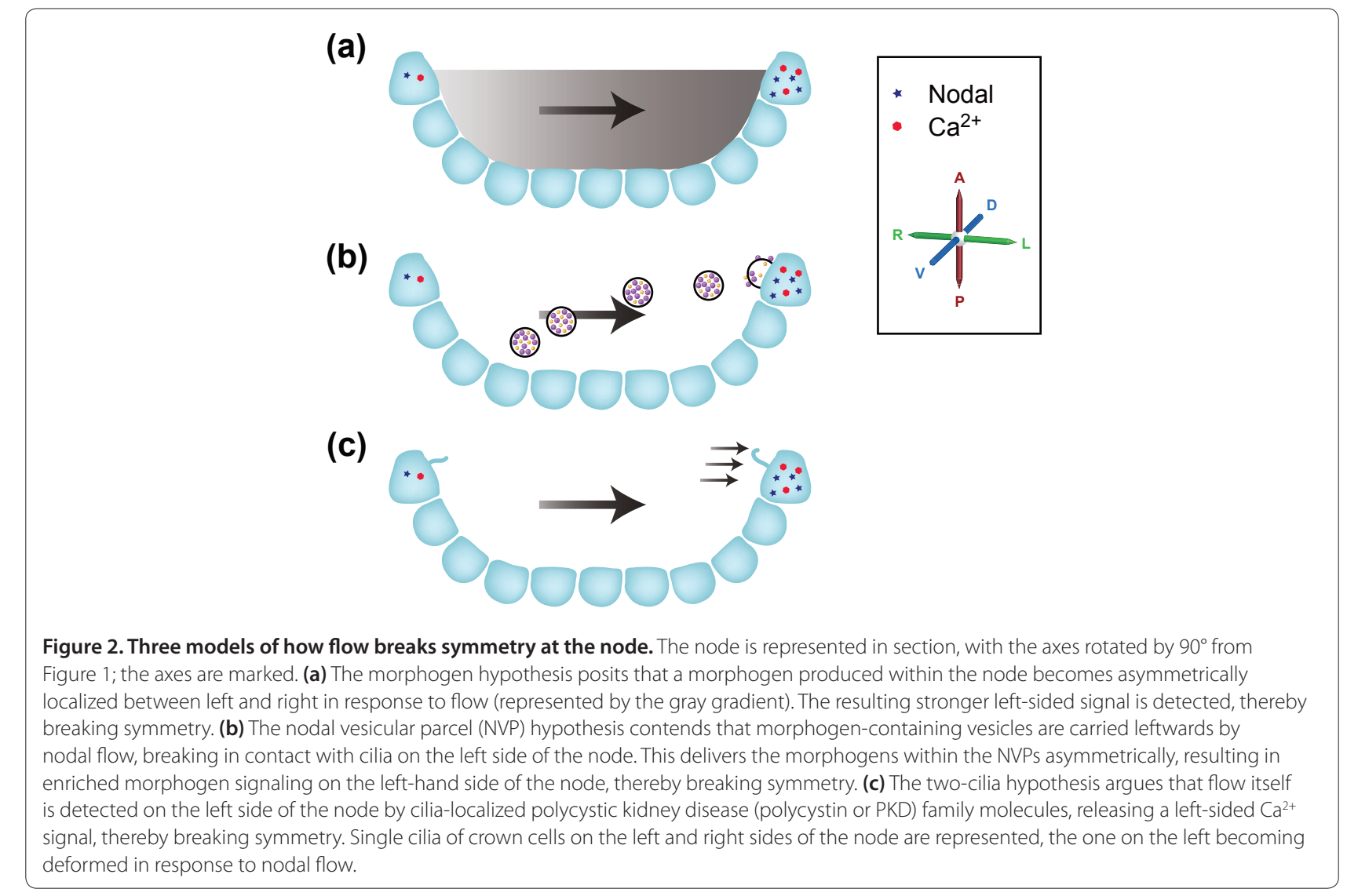

molecules between 15 and $50 \mathrm{kDa}$ in size, although the nature of the morphogen and the receptors are unknown $[28,29]$. A second hypothesis, the 'nodal vesicular parcel (NVP) hypothesis' posits the presence of membranebounded vesicles that are carried leftwards, breaking in a cilia-dependent fashion on the left side of the node where they deliver a cargo of morphogens [30]. Although very appealing, elements of this hypothesis (such as the mechanism of NVP breaking) clearly need to be modified [31]. Finally, the 'two-cilia hypothesis' argues that immotile sensory cilia detect flow directly on the left- but not the right-hand side of the node [17]. This model was predicated on the known function of the polycystic kidney disease $1(P k d 1)$ and polycystic kidney disease $2(P k d 2)$ genes in the kidney - the proteins encoded by these genes form a complex that detects urine flow and gives rise to a $\mathrm{Ca}^{2+}$ signal in response [32]. Although $P k d 1$ is not required for L-R determination [33], both $P k d 2$ and the $P k d 1$ homologue Pkd1-like 1 ( $P k d 1 l 1$ ) are involved in L-R patterning, being needed for the embryo to respond to nodal flow $[34,35]$. However, whether nodal flow pushing outwards on the left-hand side of the node can truly be differentiated from the pull exerted by nodal flow on the right-hand side of the node, a requirement of the twocilia model, has been questioned [36]. For all these models, the outcome is an asymmetric (L greater than $\mathrm{R}$ ) $\mathrm{Ca}^{2+}$ signal at the node. Currently, only the two-cilia hypothesis (and the known function of Pkd1l1/Pkd2) provides a mechanism to explain how this signal might be generated [17].

\section{Investigating ciliary function}

A recent study from Hamada and colleagues (Shinohara et al. [37]) utilizes a mixture of genetics, biophysics and imaging to examine the establishment of L-R asymmetry at the node. The authors make the striking finding that just two rotating cilia are sufficient to break L-R symmetry. In previous studies, nodal flow has been examined by following the movement of small numbers of particles across the node, allowing overall directionality and speed of flow to be assessed. For this study Shinohara et al. used an approach called particle image velocimetry (PIV), which they have customized for nodal-flow analysis [38]. Utilizing a high density of fluorescent beads within a living node and high-speed confocal imaging of a single optical plane, they followed small variations in particle position over many frames, building up a vector map of flow and forces across the entire node. At a local level this provides far more information than the particle-tracking approaches used up to now, and it seems likely that PIV 
will become a new standard for the field. With PIV analysis Shinohara et al. confirm that the early node (8.0 day embryo) has a weak leftward flow, which they demonstrate to be present at the time when the first asymmetric gene expression becomes apparent at the node: asymmetry of Cerberus-like 2 (Cerl2; also known as Dand5), an antagonist of Nodal signaling expressed more strongly on the right than the left side of the node. However, asymmetry of the Nodal cascade in the LPM occurs slightly later, once a stronger, more robust, leftwards nodal flow is acting at around the two- to threesomite stage (8.25-day embryo). Using a non-toxic viscous solution (methylcellulose), Shinohara et al. slowed, and even stopped, nodal flow. This allowed them to demonstrate that only a weak flow and/or a small temporal window of flow is required to break L-R symmetry and drive asymmetric gene expression at the node ( $\mathrm{Cerl}$ ) and in the left LPM (the Nodal cascade).

In order to investigate the role of altered nodal flow in greater detail, Shinohara et al. sought genetic approaches to perturb it. The $R f x 3$ locus encodes a transcription factor required for normal ciliogenesis in the node; mutation of this gene leads to a massive reduction in nodal cilia number and to embryos demonstrating overt L-R patterning defects [39]. Loss of the Dpcd (deleted in primary ciliary dyskinesia) locus similarly results in L-R patterning defects [40]. Both loci show incomplete penetrance, which led Shinohara et al. to examine Rfx3mutant embryos in greater detail [37]. Analysis of nodal cilia motility by light microscopy revealed that a few rotating cilia were present in these nodes. By maintaining the embryos in culture, the authors were able to image nodal cilia motility and correlate it with subsequent asymmetric gene expression. They found mildly affected embryos to have four or five rotating cilia, accompanied by normal L-R asymmetric gene expression. In contrast, severely affected embryos had at most a single rotating cilium and showed symmetrical Cerl 2 expression at the node and complete absence of LPM Nodal expression. Further analysis revealed that only two rotating cilia were required to establish normal sidedness. In embryos with three or more rotating cilia, the addition of methylcellulose to reduce flow resulted in loss of sidedness, underlining the role of the remaining level of flow in situs determination. Finally, the position of the rotating cilia within the node (whether they were near the left or right side) was addressed, and strikingly, it emerged that their position within the node bore no relationship to their ability to determine situs: something that might have implications for all three models. Intriguingly, there also seems to be a reduction in the number of immotile cilia at the periphery of the node in these embryos, although this clearly does not affect their ability to detect flow.
It is striking that the findings of Shinohara et al. [37] argue for only a few motile cilia being required to establish L-R asymmetry, when perhaps 200 such cilia are present within a wild-type node. This raises the question of whether this apparent excess of cilia is truly required, or whether it is an evolutionary aberration or hangover. Unused function tends to be lost when evolutionary selection pressure is removed, as in the case of eye and pigment loss in cave-dwelling animals [41]. Three obvious possible explanations present themselves. First, the presence of higher numbers of motile cilia and prolonged flow could have subtle effects on L-R determination that are not being assessed in these studies, possibly influencing the precise timing or extent of asymmetric gene expression, or some other unknown event downstream of nodal flow. The final outcome of these events on the anatomy and physiology of the adult mouse is what is being selected. Second, the presence of many motile cilia might add robustness to the symmetry-breaking event such that deleterious outcomes (affecting cardiac patterning, for example) become extremely rare. Third, the system may not currently be under selection. In this case we might expect a loss of function to be occurring, and perhaps for variation to be evident between different strains and species of mice. Studies in other types of organism and the production of adult mice that have developed from embryos with small numbers of motile cilia may be able to shed some light on this.

Shinohara et al. do not directly address the question of what mechanism might underlie flow sensing in the node. The weak flow produced by two rotating cilia would primarily change morphogen concentrations only very locally, and the authors surmise that this would slow down, but not necessarily destroy, a morphogen-based mechanism. The impact of weak flow on mechanosensation (in the two-cilia model) would also be noticeable, although the authors argue how it might be possible for forces created by these cilia to be directly transduced (almost instantaneously) across the node. On the basis of developmental timing, they argue that the two-cilia model is more likely to be true.

In a subsequent study, Hamada and colleagues (Yoshiba et al. [42]) have addressed aspects of the mechanism downstream of nodal flow. They have investigated the role of cilia and Pkd2 in the crown cells that surround the edge of the node (Figure 1), cells that contain primarily immotile cilia. As a result of the speed at which the early embryo grows and develops, conditional gene deletion in the node is technically challenging, and it is difficult to establish whether all protein has been lost from a cell. The authors have elegantly overcome such worries by analyzing null-mutant embryos into which regionalized gene expression has been reintroduced by transgenesis. In this way they reveal that expression of $P k d 2$ (a gene 


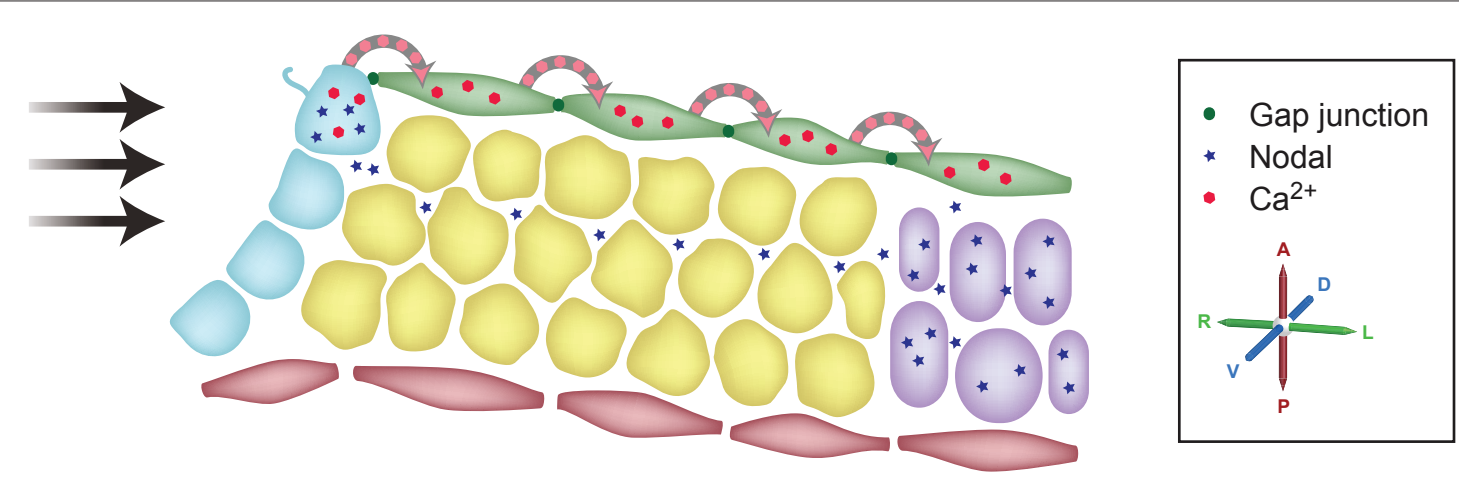

Figure 3. Two models for communicating signals from the node to the left lateral plate. A cartoon representation (not to scale) of a section through the left side of the embryo, including the left side of the node (as represented in Figure 2) and tissues lateral to the node. The cells of the node are shown in blue, the endoderm in green, the ectoderm in red, paraxial mesoderm in yellow and lateral plate mesoderm in purple. Viotti and colleagues' [49] and Saund and colleagues' work [51] argues that calcium signaling, via gap junctions, carries signals from the node leftwards through the endoderm. Oki and colleagues' analyses [48] argue that Nodal protein itself travels leftwards through an extracellular, but intraembryonic, route and directly activates the Nodal locus in the lateral plate.

normally broadly expressed in the early embryo) is required solely in the node crown cells for normal L-R patterning to occur; expression driven specifically in the remainder of the node did not rescue L-R patterning. They then showed that $\mathrm{Pkd} 2$ protein must be localized to cilia for it to function in L-R patterning. Finally, utilizing the Kif3a-null mutant (Kif3a encodes a motor protein required for cilia formation), Yoshiba et al. created embryos in which cilia were present only in the node crown cells. By then applying an artificial flow across the node, they were able to activate the normal downstream L-R pathway in these mice. This led them to propose a model in which flow is detected through cilia-localized $\mathrm{Pkd} 2$ protein in node crown cells, which in turn leads to repression of Cerl2 on the left side of the node. While these data fit well with the two-cilia hypothesis, the mechanism by which flow or a morphogen is detected remains unaddressed. Clearly, Pkd111 must be a prime candidate for performing this function, although it remains to be established whether $\mathrm{Pkd} 111$ responds to a morphogen or to flow [34,43].

\section{Transferring asymmetry from the node: intra- or extracellular communication?}

How asymmetric information moves from the node out to the LPM is also the subject of competing hypotheses (Figure 3). When Brueckner and colleagues [17] originally described the generation of asymmetric $\mathrm{Ca}^{2+}$ at the node, they commented that (at least on occasions) the asymmetric signal spread as far as the lateral plate. This clearly provides one possible mechanism by which asymmetric information might travel out from the node - by $\mathrm{Ca}^{2+}$ moving intracellularly from cell to cell. In contrast, Hamada and colleagues built on two other facts: that Nodal expression at the node is required for Nodal activation in the LPM $[44,45]$; and the recognized ability of Nodal to activate its own expression [46,47]. They proposed that asymmetrically distributed extracellular Nodal protein at the node is transported more readily leftwards, through the extracellular matrix [48]. Two recent papers provide significant advances in our understanding of the mechanisms of these processes.

In one paper, Hadjantonakis and colleagues (Viotti et al. [49]) report that Sox17-null embryos exhibit defective L-R patterning; Sox17 encodes an Sry-box containing protein that is required for normal definitive endoderm formation [50]. These embryos do not express the Nodal cascade in either the left or the right LPM but, significantly, retain asymmetric gene expression at the node. This clearly suggests that communication between the node and the LPM requires the definitive endoderm, a result reminiscent of the observations of McGrath et al. [17]. Together, these data suggested that calcium-induced calcium release was signaling between cells in the definitive endoderm; such signals are known to travel via gap junctions. By surveying gap-junction protein expression in normal embryos, Viotti et al. found that the core gapjunction protein connexin 43 (also known as Gja1) was expressed in the definitive endoderm. However, it proved to be absent from the endoderm of Sox 17 mutant embryos. Loss of connexin 43 does not, of course, directly prove a loss of gap-junction function. Viotti et al. therefore assessed this by injecting dye into definitive endoderm cells, revealing that in wild-type embryos small, but not large, dye molecules moved between cells through gap junctions. The dyes did not cross into other cell lineages and, significantly, never moved into or crossed the midline, demonstrating that the left and right sides of the embryo are distinct and not linked by gap junctions. In the absence of such a barrier, both sides of the embryo 
would be activated by any signal mediated through the endoderm. When Sox17-null embryos were examined, the dyes did not migrate between cells, demonstrating a loss of gap-junction connections. The role of gap junctions was firmly established when pharmacological agents were used to block gap-junction function in wildtype embryos, and this reproduced the L-R patterning defects seen in the Sox17-null embryos. This work shows that the definitive endoderm and gap junctions are required for the transfer of L-R asymmetry signals from the node to the LPM.

While Viotti et al. have shown that a gap-junctiondependent $\mathrm{Ca}^{2+}$ signal can travel from the node to the left LPM, they stop short of providing a mechanism by which $\mathrm{Ca}^{2+}$ might activate Nodal expression in the LPM. In contrast, a model proposed by Oki et al. [48] does provide an explanation for Nodal activation in the LPM Nodal moving out from the node. However, the Oki model provides no explanation of the role of asymmetric $\mathrm{Ca}^{2+}$ signaling in the endoderm. It is of course tempting to combine these two models: a simple combined ViottiOki model might propose that calcium signaling in the endoderm influences the underlying cell matrix, which in turn affects the ability of Nodal protein to propagate from the node to the left LPM.In a contemporaneous study, Saijoh and colleagues (Saund et al. [51]) have independently identified the role of Sox17 and the definitive endoderm in L-R patterning [51]. These authors specifically investigated the link between loss of Sox17 function and the proposed intra-embryonic, extracellular route for Nodal. They examined extracellular matrix proteins previously implicated in the translocation of Nodal protein, revealing a defect in a proportion of Sox17 mutant embryos. However, a smaller proportion of embryos exhibited such defects than exhibited abnormal L-R patterning. Saund et al. therefore argue that this change is not the primary cause of the L-R defects in the Sox 17 mutants. Of course, this does not fully exclude the possibility that a combination of similar defects, including those changes that they detected, are influencing intra-embryonic extracellular transport of Nodal to the left LPM.

\section{Prospects and questions}

Although significant advances in the understanding of L-R determination have been made, gaps still remain. Even following these most recent studies, it is evident that we do not fully understand how nodal flow leads to L-R asymmetry. Both the two-cilia and morphogen hypotheses remain entirely plausible, and both have their champions within the field. Discriminating between them is not simple, and short of the identification of the putative ligand central to the morphogen hypothesis, may remain so, as if the two-cilia hypothesis is correct, no such morphogen exists. These studies are moving into the realm of the biophysicist, and will increasingly require an understanding of equations and modeling. An appreciation of the node as a (low Reynolds number) microfluidic environment, in which inertia effectively disappears, is required. In such an environment, our 'real-world' experiences can lead us to expect outcomes that are in fact incorrect, taking us far from reality; a very accessible discussion of such environments, and life at low Reynolds number, is available in the excellent article by Purcell [52].

Is it possible that both the two-cilia and morphogen mechanisms are acting in concert, providing two signals of 'leftness' in the node? Clearly, in such a scenario these might both have an impact on Nodal expression, but it is also possible to envisage that they might have different targets. Indeed, Pitx2, the most downstream gene of the Nodal signaling cascade, does not affect gross cardiac situs [26], implying that there must be additional asymmetrically expressed loci controlling this process. The simple explanation is that such loci are directly controlled by asymmetric Nodal expression in the LPM; in other words, that there are additional unidentified Nodal target genes at the end of the Nodal cascade. However, arguments also exist for Nodal-independent asymmetric gene expression in the LPM: analysis of the Ablim 1 locus reveals it to be asymmetrically expressed in the left but not right LPM in the absence of Nodal expression [53]. Moreover, both galanin ( $\mathrm{Gal}$ ), a neuropeptide with a role in neuronal inhibition, and Pitx2 retain L-R asymmetric expression in early cardiac tissue (at the anterior end of the LPM) in the absence of the Nodal co-receptor Cryptic, which is required for Nodal expression in the LPM [54]. Whether these loci are affected by one rather than another of the putative mechanisms remains uninvestigated. Further uncertainty remains downstream of Pitx2, where the target genes that facilitate asymmetric morphogenesis remain to be identified.

The presence of very early L-R asymmetry, established by the initial cleavage of the embryo, has been strongly argued in Xenopus [55]. However, few such suggestions have been made for the mouse. The one exception is a purely embryological study by Gardner [56], which revealed that manipulation of the early blastomeres can affect the direction of embryonic axial rotation, but not other aspects of situs. While at present there is no explanation of how this might function at a molecular level, it implies that another system of L-R determination may be acting in addition to that driven by nodal flow.

The intriguing question of how neural L-R asymmetry is established in mammals remains largely unanswered. Is it linked with, or independent of, visceral asymmetry? In zebrafish, there is asymmetric expression of the Nodal cascade in the habenular nucleus of the brain (on the left 
but not right side), but no such association has been detected in the mouse or suggested in humans. The human LMO4 locus shows asymmetric expression in the brain of 12-week-old human embryos, with stronger right-sided than left-sided expression [57]. This is, however, at a much later stage of development than the establishment of visceral asymmetry, suggesting that it may be a downstream event and/or that neural asymmetry is entirely independent of visceral asymmetry. Intriguingly, expression of the mouse Lmo4 locus, while also asymmetrical, appears to be random, with individual embryos demonstrating a left- or a right-sided preference in their expression [57]. Whether this reflects innate differences between mouse and human brains (and neural asymmetry) remains to be determined.

Continued study, in the mouse as well as in other organisms, will be required to unravel the nature of L-R determination and its evolution. Understanding the differences between the mechanisms by which various organisms pattern their L-R axes should reveal which elements of the process have remained constant and which have varied. Ultimately, this knowledge will provide insight into the evolution of L-R asymmetry, how processes such as nodal flow have been gained and lost in different organisms, and perhaps to our understanding the evolutionary driving forces involved.

\section{Acknowledgements}

DPN is supported by the UK Medical Research Council. I thank Daniel Grimes and other members of my group for discussion and for reading drafts, and

Steve Thomas for extensive work on the figures.

Published: 19 December 2012

\section{References}

1. Neville AC: Animal asymmetry. Studies Bio/ 1976, 67

2. Ramsdell AF: Left-right asymmetry and congenital cardiac defects: Getting to the heart of the matter in vertebrate left-right axis determination. Dev Biol 2005, 288:1-20.

3. Franco D, Campione M: The role of Pitx2 during cardiac development. Linking left-right signaling and congenital heart diseases. Trends Cardiovasc Med 2003, 13:157-163.

4. Kathiriya IS, Srivastava D: Left-right asymmetry and cardiac looping: implications for cardiac development and congenital heart disease. Am J Med Genet 2000, 97:271-279.

5. Drummond IA: Cilia functions in development. Curr Opin Cell Biol 2012, 24:24-30.

6. Nakamura T, Hamada H: Left-right patterning: conserved and divergent mechanisms. Development 2012, 139:3257-3262.

7. Carmi R, Magee CA, Neill CA, Karrer FM: Extrahepatic biliary atresia and associated anomalies: etiologic heterogeneity suggested by distinctive patterns of associations. Am J Med Genet 1993, 45:683-693.

8. Nonaka S, Tanaka Y, Okada Y, Takeda S, Harada A, Kanai Y, Kido M, Hirokawa N: Randomization of left-right asymmetry due to loss of nodal cilia generating leftward flow of extraembryonic fluid in mice lacking KIF3B motor protein. Cell 1998, 95:829-837.

9. Feistel K, Blum M: Three types of cilia including a novel 9+4 axoneme on the notochordal plate of the rabbit embryo. Dev Dyn 2006, 235:3348-3358.

10. Essner JJ, Vogan KJ, Wagner MK, Tabin CJ, Yost HJ, Brueckner M: Conserved function for embryonic nodal cilia. Nature 2002, 418:37-38.

11. Kramer-Zucker AG, Olale F, Haycraft CJ, Yoder BK, Schier AF, Drummond IA Cilia-driven fluid flow in the zebrafish pronephros, brain and Kupffer's vesicle is required for normal organogenesis. Development 2005, 132:1907-1921.
12. Hirokawa N, Tanaka Y, Okada Y: Cilia, KIF3 molecular motor and nodal flow. Curr Opin Cell Biol 2012, 24:31-39.

13. Okada Y, Nonaka S, Tanaka Y, Saijoh Y, Hamada H, Hirokawa N: Abnormal nodal flow precedes situs inversus in iv and inv mice. Mol Cell 1999, 4:459-468.

14. Nonaka S, Shiratori H, Saijoh Y, Hamada H: Determination of left-right patterning of the mouse embryo by artificial nodal flow. Nature 2002, 418:96-99.

15. Brueckner M: Heterotaxia, congenital heart disease, and primary ciliary dyskinesia. Circulation 2007, 115:2793-2795.

16. Kartagener M, Horlacher A: Bronchiektasen bei Situs viscerum inversus. Scweiz Med Wochenschr 1935, 16:782-784.

17. McGrath J, Somlo S, Makova S, Tian X, Brueckner M: Two populations of node monocilia initiate left-right asymmetry in the mouse. Cell 2003, 114:61-73.

18. Sakuma R, Ohnishi Yi Y, Meno C, Fujii H, Juan H, Takeuchi J, Ogura T, Li E, Miyazono K, Hamada H: Inhibition of Nodal signaling by Lefty mediated through interaction with common receptors and efficient diffusion. Genes Cells 2002, 7:401-412.

19. Marjoram L, Wright C: Rapid differential transport of Nodal and Lefty on sulfated proteoglycan-rich extracellular matrix regulates left-right asymmetry in Xenopus. Development 2011, 138:475-485.

20. Muller P, Rogers KW, Jordan BM, Lee JS, Robson D, Ramanathan S, Schier AF: Differential diffusivity of Nodal and Lefty underlies a reaction-diffusion patterning system. Science 2012, 336:721-724.

21. Meno C, Takeuchi J, Sakuma R, Koshiba-Takeuchi K, Ohishi S, Saijoh Y, Miyazaki J, ten Dijke P, Ogura T, Hamada H: Diffusion of nodal signaling activity in the absence of the feedback inhibitor Lefty2. Dev Cell 2001, 1:127-138.

22. Piedra ME, Icardo JM, Albajar M, Rodriguez-Rey JC, Ros MA: Pitx2 participates in the late phase of the pathway controlling left-right asymmetry. Cell 1998, 94:319-324.

23. Ryan AK, Blumberg B, Rodriguez-Esteban C, Yonei-Tamura S, Tamura K, Tsukui T, de la Peña J, Sabbagh W, Greenwald J, Choe S, Norris DP, Robertson EJ, Evans RM, Rosenfeld MG, Izpisúa Belmonte JC: Pitx2 determines left-right asymmetry of internal organs in vertebrates. Nature 1998, 394:545-551.

24. Yoshioka H, Meno C, Koshiba K, Sugihara M, Itoh H, Ishimaru Y, Inoue T, Ohuchi H, Semina EV, Murray JC, Hamada H, Noji S: Pitx2, a bicoid-type homeobox gene, is involved in a lefty-signaling pathway in determination of left-right asymmetry. Cell 1998, 94:299-305.

25. Logan M, Pagan-Westphal SM, Smith DM, Paganessi L, Tabin CJ: The transcription factor Pitx2 mediates situs-specific morphogenesis in response to left-right asymmetric signals. Cell 1998, 94:307-317.

26. Liu C, Liu W, Lu MF, Brown NA, Martin JF: Regulation of left-right asymmetry by thresholds of Pitx2c activity. Development 2001, 128:2039-2048.

27. Liu C, Liu W, Palie J, Lu MF, Brown NA, Martin JF: Pitx2c patterns anterior myocardium and aortic arch vessels and is required for local cell movement into atrioventricular cushions. Development 2002, 129:5081-5091.

28. Cartwright JH, Piro O, Tuval I: Fluid-dynamical basis of the embryonic development of left-right asymmetry in vertebrates. Proc Natl Acad Sci U SA 2004, 101:7234-7239.

29. Okada Y, Takeda S, Tanaka Y, Belmonte JC, Hirokawa N: Mechanism of nodal flow: a conserved symmetry breaking event in left-right axis determination. Cell 2005, 121:633-644.

30. Tanaka Y, Okada Y, Hirokawa N: FGF-induced vesicular release of Sonic hedgehog and retinoic acid in leftward nodal flow is critical for left-right determination. Nature 2005, 435:172-177.

31. Cartwright JH, Piro N, Piro O, Tuval I: Fluid dynamics of nodal flow and left-right patterning in development. Dev Dyn 2008, 237:3477-3490.

32. Harris PC, Torres VE: Polycystic kidney disease. Annu Rev Med 2009, 60:321-337.

33. Karcher C, Fischer A, Schweickert A, Bitzer E, Horie S, Witzgall R, Blum M: Lack of a laterality phenotype in Pkd1 knock-out embryos correlates with absence of polycystin-1 in nodal cilia. Differentiation 2005, 73:425-432.

34. Field S, Riley KL, Grimes DT, Hilton H, Simon M, Powles-Glover N, Siggers P, Bogani D, Greenfield A, Norris DP: Pkd111 establishes left-right asymmetry and physically interacts with Pkd2. Development 2011, 138:1131-1142.

35. Pennekamp P, Karcher C, Fischer A, Schweickert A, Skryabin B, Horst J, Blum $M$, Dworniczak $B$ : The ion channel polycystin- 2 is required for left-right axis determination in mice. Curr Biol 2002, 12:938-943.

36. Supatto W, Vermot J: From cilia hydrodynamics to zebrafish embryonic development. Curr Top Dev Biol 2011, 95:33-66. 
37. Shinohara K, Kawasumi A, Takamatsu A, Yoshiba S, Botilde Y, Motoyama N, Reith W, Durand B, Shiratori H, Hamada H: Two rotating cilia in the node cavity are sufficient to break left-right symmetry in the mouse embryo. Nat Commun 2012, 3:622

38. Hashimoto M, Shinohara K, Wang J, Ikeuchi S, Yoshiba S, Meno C, Nonaka S, Takada S, Hatta K, Wynshaw-Boris A, Hamada H: Planar polarization of node cells determines the rotational axis of node cilia. Nat Cell Bio/ 2010, 12:170-176.

39. Bonnafe E, Touka M, AitLounis A, Baas D, Barras E, Ucla C, Moreau A, Flamant F, Dubruille R, Couble P, Collignon J, Durand B, Reith W: The transcription factor RFX3 directs nodal cilium development and left-right asymmetry specification. Mol Cell Biol 2004, 24:4417-4427.

40. Vogel P, Read R, Hansen GM, Freay LC, Zambrowicz BP, Sands AT: Situs inversus in Dpcd/Poll-/-, Nme7-/- , and Pkd111-/- mice. Vet Patho/ 2010 47:120-131.

41. Jeffery WR: Regressive evolution in Astyanax cavefish. Annu Rev Genet 2009, 43:25-47.

42. Yoshiba S, Shiratori H, Kuo IY, Kawasumi A, Shinohara K, Nonaka S, Asai Y, Sasaki G, Belo JA, Sasaki H, Nakai J, Dworniczak B, Ehrlich BE, Pennekamp P, Hamada $\mathrm{H}$ : Cilia at the node of mouse embryos sense fluid flow for left-right determination via Pkd2. Science 2012, 338:226-231.

43. Kamura K, Kobayashi D, Uehara Y, Koshida S, lijima N, Kudo A, Yokoyama T, Takeda H: Pkd111 complexes with Pkd2 on motile cilia and functions to establish the left-right axis. Development 2011, 138:1121-1129.

44. Brennan J, Norris DP, Robertson EJ: Nodal activity in the node governs leftright asymmetry. Genes Dev 2002, 16:2339-2344.

45. Saijoh Y, Oki S, Ohishi S, Hamada H: Left-right patterning of the mouse lateral plate requires nodal produced in the node. Dev Bio/ 2003, 256:160-172.

46. Adachi H, Saijoh Y, Mochida K, Ohishi S, Hashiguchi H, Hirao A, Hamada H: Determination of left/right asymmetric expression of nodal by a left sidespecific enhancer with sequence similarity to a lefty-2 enhancer. Genes Dev 1999, 13:1589-1600

47. Norris DP, Robertson EJ: Asymmetric and node-specific nodal expression patterns are controlled by two distinct cis-acting regulatory elements. Genes Dev 1999, 13:1575-1588.

48. Oki S, Hashimoto R, Okui Y, Shen MM, Mekada E, Otani H, Saijoh Y, Hamada H: Sulfated glycosaminoglycans are necessary for Nodal signal transmission from the node to the left lateral plate in the mouse embryo. Development 2007, 134:3893-3904.

49. Viotti M, Niu L, Shi SH, Hadjantonakis AK: Role of the gut endoderm in relaying left-right patterning in mice. PLOS Biol 2012, 10:e1001276.

50. Kanai-Azuma M, Kanai Y, Gad JM, Tajima Y, Taya C, Kurohmaru M, Sanai Y, Yonekawa H, Yazaki K, Tam PP, Hayashi Y: Depletion of definitive gut endoderm in Sox17-null mutant mice. Development 2002, 129:2367-2379.

51. Saund RS, Kanai-Azuma M, Kanai Y, Kim I, Lucero MT, Saijoh Y: Gut endoderm is involved in the transfer of left-right asymmetry from the node to the lateral plate mesoderm in the mouse embryo. Development 2012, 139:2426-2435.

52. Purcell EM: Life at low Reynolds number. Am J Physics 1977, 45:3-11.

53. Stevens J, Ermakov A, Braganca J, Hilton H, Underhill P, Bhattacharya S, Brown NA, Norris DP: Analysis of the asymmetrically expressed Ablim 1 locus reveals existence of a lateral plate Nodal-independent left sided signal and an early, left-right independent role for nodal flow. BMC Dev Bio/ 2010 10:54.

54. Schweickert A, Deissler K, Britsch S, Albrecht M, Ehmann H, Mauch V, Gaio U, Blum M: Left-asymmetric expression of Galanin in the linear heart tube of the mouse embryo is independent of the nodal co-receptor gene cryptic. Dev Dyn 2008, 237:3557-3564.

55. Levin M: Left-right asymmetry in embryonic development: a comprehensive review. Mech Dev 2005, 122:3-25.

56. Gardner RL: Normal bias in the direction of fetal rotation depends on blastomere composition during early cleavage in the mouse. PLOS ONE 2010, 5:e9610.

57. Sun T, Patoine C, Abu-Khalil A, Visvader J, Sum E, Cherry TJ, Orkin SH, Geschwind DH, Walsh CA: Early asymmetry of gene transcription between embryonic human left and right cerebral cortex. Science 2005, 308:1794-1798.

doi:10.1186/1741-7007-10-102

Cite this article as: Norris DP: Cilia, calcium and the basis of left-right asymmetry. BMC Biology 2012, 10:102 